B. Chatterjee
U. Bürgi

\section{Syncope of a drug addict -}

\section{a special case}

Sirs: A considerable number of drugs can induce a prolongation of cardiac repolarisation (QT interval) and thereby predispose to the development of torsades de pointes. A few reports [1-4] have discussed a prolongation of the QT interval by methadone used in the treatment of opiate addicts. In the present report the case of a young heroine addict with a collapse is described. The ECG showed QT interval prolongation and torsades de pointes, probably due to methadone therapy.

\section{Case report}

The subject of this case report is a 33-year-old female former heroin addict under controlled methadone therapy ( $120 \mathrm{mg} /$ day). She also regularly consumed alcohol and benzodiazepines. One week prior to the cardiac events described below, she received analgesics and inhalation therapy from her general

Received: 16 February 2006

Accepted: 7 June 2006

Published online: 1 August 2006

Bidisha Chatterjee, MD ( $\bullet$ ) Ulrich Bürgi

Department of General Internal Medicine

Inselspital/University Hospital

3010 Bern, Switzerland

Tel.: +41-31/6321098

Fax: +41-31/6328885

E-Mail: bidisha.chatterjee@insel.ch practitioner because of symptoms of bronchitis and chest pain. Use of a salmeterol/fluticason inhaler repeatedly caused dizziness, and the patient stopped using it. The analgesic was Etodolac $(300 \mathrm{mg}$ tablets), an NSAID, which she took irregularly during one week. On the admission day the patient called the ambulance because she had had a very bad night, felt exhausted, complained of chest pain, felt dizzy, almost collapsed and experienced convulsions. In the ambulance she lost consciousness and the ECG recording showed ventricular tachycardia requiring defibrillation (Fig. 1).

In the emergency room the patient was awake but complained of chest pain. A 12 lead ECG showed sinus rhythm, with frequent ventricular extra beats and a markedly prolonged QT interval $(560 \mathrm{~ms} /$ QTc 626 ms, Fig. 2).

In the intensive care unit several bouts of ventricular tachycardia were recorded, some of which were self-limiting while others required defibrillation. Analysis of the rhythm disturbances showed not only ventricular runs but also torsades de pointes (Fig. 3). Laboratory measurements were normal with the exception of elevated liver enzymes. Potassium and magnesium levels were in the low normal range. Methadone was stopped and replaced by morphine i.v. which was then gradually reduced. Magnesium and potassium were given i.v. to achieve high normal values, and $\beta$-blockers to control the intermittently rapid heart rate. Considering the fact that with a slow pulse the QT interval becomes even longer and also the vulnerable phase to develop tachyarrhythmias, $\beta$-blockers were used with the aim of reducing the heart rate down to 100 beats per minute.

Under this treatment cardiac rhythm disturbances disappeared. Seven days after stopping methadone the QT interval had returned to normal $(440 \mathrm{~ms}$, Fig. 4). 


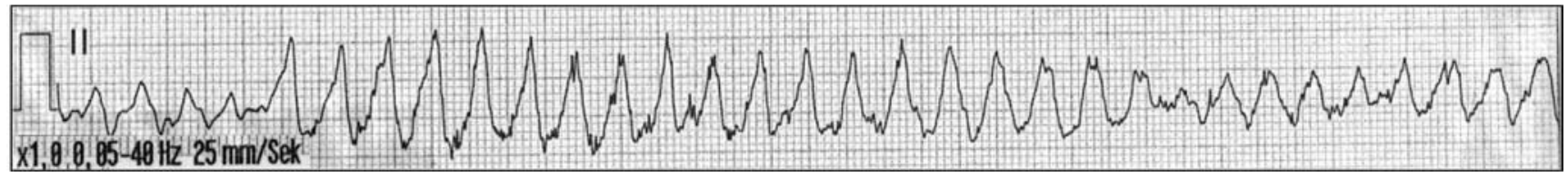

Fig. 1 Rhythm slip of ECG monitor in the ambulance showing ventricular tachycardia

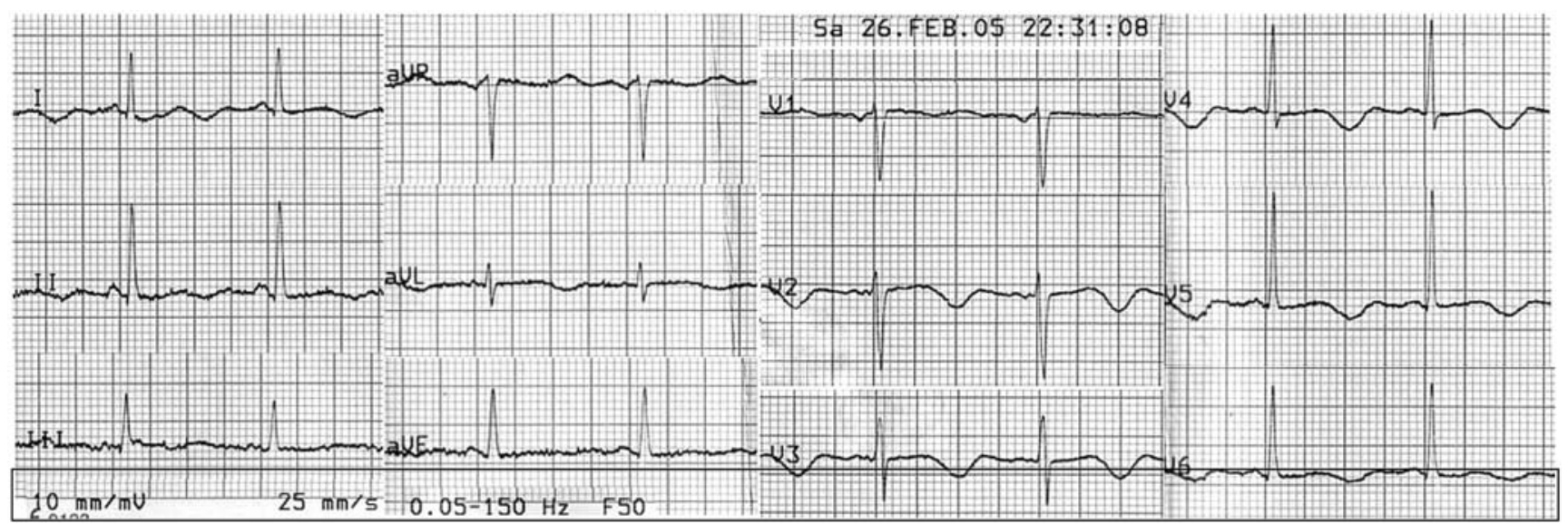

Fig. 212 lead ECG at time of admission showing a QT interval of $560 \mathrm{~ms}$ (QTc $626 \mathrm{~ms}$ )

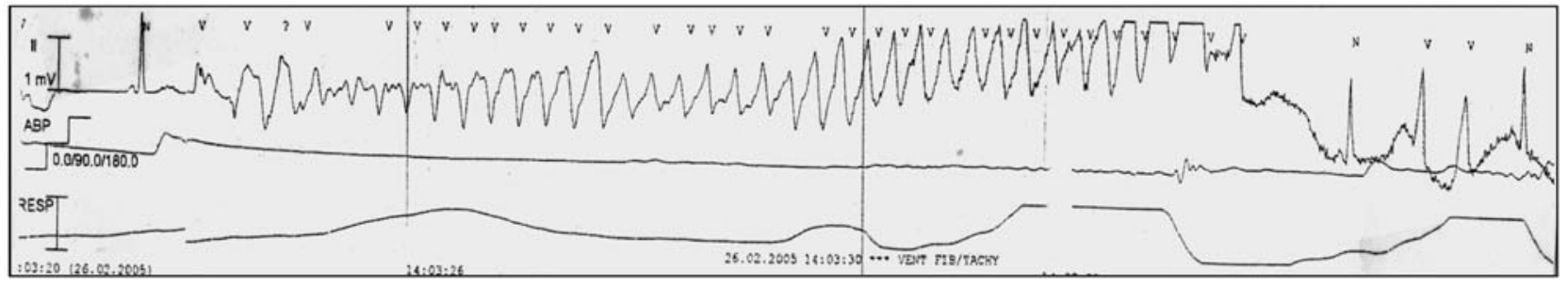

Fig. 3 Rhythm slip of monitor on ICU showing Torsade de pointes
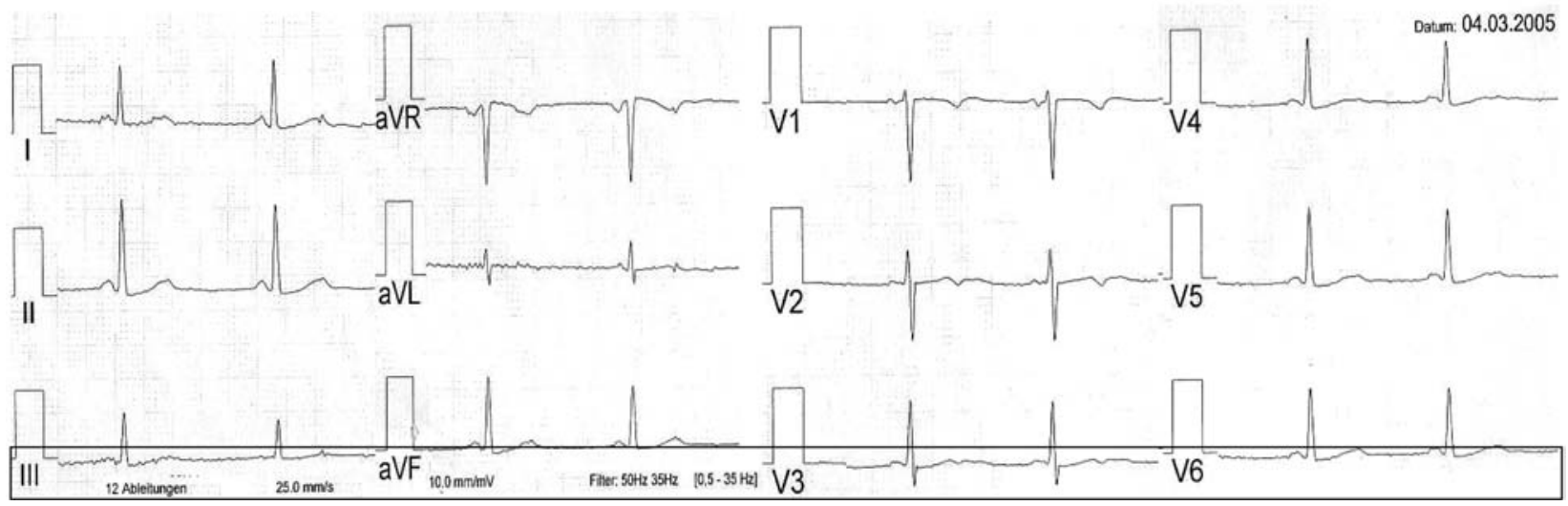

Fig. 4 The 12 lead ECG after cessation of methadone showing a QT interval of $440 \mathrm{~ms}$ (QTc $440 \mathrm{~ms}$ ) 
The patient had been receiving methadone therapy for two years. Eighteen months previously she had been hospitalised because of alcohol induced acute pancreatitis. At this time she had been receiving $90 \mathrm{mg}$ methadone/day and the QT interval was already markedly prolonged (560 ms, QTc $650 \mathrm{~ms}$ ).

\section{Discussion}

We strongly suspect that the torsades de pointes described here were methadone induced. Prolonged QT interval and torsades de pointes during methadone therapy have been described in some case reports [1-3].

At the molecular level, 1- $\alpha$-acetylmethadol (methadone) has been demonstrated to block cloned HERG cardiac $\mathrm{K}^{+}$channels [4]. This mechanism could lead to a QT interval prolongation and ventricular arrhythmias. Methadone is metabolized via CYP $3 \mathrm{~A} 4$ as well as Salmeterol and for example grapefruit juice or cocain which the patient assured not to have consumed. It is first metabolized in the liver and then eliminated through the kidneys. Simultaneous therapy with Diazepam can slow down the metabolism. Our patient had quite normal liver function despite her regular alcohol consumption and she never took Diazepam but Lorazepam and Zolpidem [5]. Etodolac, which does not cause QT prolongation and Salmeterol, for which QT prolongation has only been described when used in supra-therapeutic doses, are unlikely to have triggered the patient's rhythm disturbances, particularly since she only used these drugs for a short time prior to the cardiac event [6].

The normalisation of the long QT interval after stopping methadone makes it most likely that the torsades de pointes were caused by methadone, possibly facilitated by the borderline low potassium and magnesium levels.

Since a considerable number of heroin/opiate addicts are treated with methadone, it is recommend that these patients should have ECG controls to check the QT interval.

Acknowledgements We thank Dr. M.E. Bürgi-Saville for editorial assistance.

\section{References}

1. Gil M, Sala M, Anguera I, Chapinal O, Cervantes M, Guma JR, Segura F (2003) QT prolongation and torsade de pointes in patients infected with human immunodeficiency virus and treated with methadone. Am J Cardiol 92:995-997

2. Maremanni I, Pacini M, Cesaroni C Lovrecic M, Perugi G, Tagliamonte A (2005) QTc interval prolongation in patients on long-term methadone maintenance therapy. Eur Addict Res 11:44-49

3. Decerf JA, Gressens B, Brohet C, Liolios A, Hantson P (2004) Can methadone prolong the QT interval? Intensive Care Med 30:1690-1691

4. Kang J, Chen XL, Wang H, Rampe D (2003) Interactions of the narcotic 1alpha-acetylmethadol with human cardiac $\mathrm{K}^{+}$channels. Eur J Pharmacol 458:25-29

5. www.qtdrugs.org
6. Peters $\mathrm{S}$, Rust $\mathrm{H}$, Trümmel $\mathrm{M}$, Brattström A (2000) Familial hypertrophic cardiomyopathy associated with prolongation of the QT interval. Z Kardiol 89(7):624-629

7. Haverkamp W, Mönnig G, Kirchhof P, Eckhardt L, Borggrefe M, Breithardt G (2001) Torsade de pointes induced by ajmaline. Z Kardiol 90(8):586-590

8. Gerhardy A, Scholtysik G, Schaad A, Haltiner R, Hess T (1998) Generating and influencing Torsade de pointes like polymorphic ventricular tachycardia in isolated guinea pig hearts. Basic Res Cardiol 93(4):285-294

9. Schreiner KD, Voss F, Senges JC, Becker R, Kraft P, Baer A, Kelemen K, Kuebler W, Vos MA, Schoels W (2004) Tridimensional activation patterns of acquired torsade de pointes tachycardias in dogs with chronic AV-Block. Basic Res Cardiol 99(4): 288-298
10. Schrickel J, Bielik H, Yang A, Schwab JO, Shlevkov N, Schimpf R, Lüderitz B, Lewalter T (2003) Amiodarone-associated torsade de pointes: relevance of concomitant cardiovascular medication in a patient with atrial fibrillation and structural heart disease. $\mathrm{Z}$ Kardiol 92(10):889-892

11. Milberg P, Reinsch N, Osada N, Wasmer K, Mönnig G, Stypmann J, Breithardt G, Haverkamp W, Eckhardt L (2005) Verapamil prevents torsade de pointes by reduction of transmural dispersion of repolarization and suppression of early afterdepolarizations in an intact heart model of LQT3. Basic Res Cardiol 100(4): 365-371 